\title{
PEMASARAN PRODUK KERAJINAN BERBASIS CLOUD MARKETPLACE
}

\author{
Sriatun $^{1)}$, M. Arfan ${ }^{2)}$, Sumardi $^{2)}$ \\ 1) Departemen Kimia, Fakultas Sains dan Matematika Universitas Diponegoro \\ ${ }^{2)}$ Departemen Teknik Elektro, Fakultas Teknik Universitas Diponegoro \\ E-mail : sumardi.undip@gmail.com
}

\begin{abstract}
Abstrak
Pengrajin keset dari kain perca di Ceper Klaten Jawa Tengah saat ini sudah mampu memproduksi keset beraneka macam karakter seperti angry bird, keropy, doraemon dan sebagainya, namun pemasarannya masih sangat terbatas sehingga masyarakat luas belum mengenal produk keset dari daerah ini. Selain itu rendahnya kemampuan SDM pengrajin dalam bidang teknologi informasi/internet menyebabkan kendala dalam berinteraksi dengan pihak lain baik konsumen maupun pensuplai bahan baku. Melalui Program IbM/PKM ini diupayakan untuk menerapkan teknologi informasi/internet guna meningkatkan pemasaran produk kerajianan keset dari kain perca melalui cloud marketplace. Penggunaan smartphone terus meningkat dan semakin murah serta dukungan pemerintah pada industri kreatif dengan teknologi digital menjadikan peluang untuk melaksanakan pemasaran secara online semakin mudah. Pemasaran melalui cloud marketplace tidak membutuhkan modal yang besar, akses mudah dengan pelayanan penuh ( $24 \mathrm{jam}$ ) pada pelanggan, biaya operasional rendah. Melalui metode pemasaran ini kreatifitas dalam mempromosikan dan mengembangkan produk kerajinan lebih terbuka sehingga dapat meningkatkan omzet penjualan.
\end{abstract}

Kata kunci: pemasaran, kerajinan keset,cloud, marketplace

\begin{abstract}
Patchwork in Ceper Klaten, Central Java is now able to produce various mats of characters such as angry bird, keropy, doraemon and so on, but the marketing is still very limited so that the public has not known the mat products from this region. In addition, the low ability of human resources craftsmen in the field of information technology/internet causing obstacles in interacting with other parties both consumers and suppliers. The IbM/PKM Program is attempted to apply information technology/internet in order to improve the marketing of keret grooming products from patchwork through cloud marketplace. Smartphone use continues to increase and cheaper and government support in creative industries with digital technology makes the opportunity to carry out online marketing easier. Marketing through the cloud marketplace does not require large capital, easy access with full service (24 hours) to customers and low operating costs. Through this marketing method creativity in promoting and developing of craft products more open so as to increase sales turnover.
\end{abstract}

Key words: marketing, craft mat, cloud, marketplace

\section{Pendahuluan}

Produksi keset dari kain perca oleh para pengrajin di Ceper Klaten Jawa Tengah terus mengalami peningkatan, namun jumlah produksi yang melimpah tidak diikuti dengan strategi pemasaran yang baik. Sebagaimana yang telah dilakukan oleh pengrajin kain perca di daerah Kabupaten Klaten, sejak beberapa tahun lalu peluang usaha ini telah diberdayakan menjadi usaha yang menguntungkan bagi sebagian masyarakat di daerah tersebut. Saat ini kapasitas produksi kerajinan dari kain perca mencapai 350 - 500 buah (untuk model persegi) atau sekitar 200 - 300 buah (model karakter) per bulan. Untuk membuat keset model karakter dibutuhkan lebih banyak bahan baku karena jahitannya sangat rapat. Pemilihan warna yang tepat dan perpaduan warna menjadi bagian penting agar model karakter seperti aslinya. Meskipun secara kuantitas produk model baru tidak sebanyak model persegi namun harga jual relatif lebih tinggi yaitu bisa mencapai lebih dari 5-7 kali dari harga model persegi. Variasi harga tergantung tingkat kesulitan dan perpaduan warna kain perca yang dipakai. Banyaknya pengrajin dari bahan kain perca di daerah tersebut menyebabkan produk berlimpah, namun pemasarannya terbatas.

Sebelumnya pengrajin kain perca belum mempunyai program/cara pemasaran yang baik karena hanya 
menunggu di rumah, mengandalkan permintaan pesanan dari konsumen dan pengepul/tengkulak. Dengan demikian omzet penjualan sangat tergantung pada permintaan dari pedagang pengepul. Dari pengepul akan dijual kembali kepada konsumen baik secara langsung maupun online. Biasanya pengepul menekan harga sehingga keuntungan produsen/pengrajin kain perca menjadi kecil padahal harga bahan baku semakin mahal.

Sebagaimana diketahui bahwa keset merupakan barang yang tidak cepat habis seperti halnya makanan atau minuman, dan bukan merupakan barang fashion yang bisa dipakai berganti-ganti sesuai dengan situasi dan kondisi konsumen. Keset produksi mitra IbM ini tahan lama atau awet tidak mudah "mbradul" karena memang kualitas jahitannya yang kuat, sehingga dimungkinkan konsumen menggunakan satu produk keset untuk jangka lama. Dengan demikian perlu strategi pemasaran dan perluasan pemasaran agar produksi maupun penjualan dapat tetap terjaga.

Berdasarkan permasalahan tersebut, maka untuk menjaga kontinyuitas dan peningkatan pemasaran, maka pada program pengabdian IbM/PKM ini diupayakan perancangan aplikasi cloud marketplace yang meliputi program pemasaran untuk pengrajin, pengelolaan stok barang. Dengan cara ini kreatifitas dalam mempromosikan dan mengembangkan produk kerajinan lebih terbuka sehingga dapat menjadikan sebagai produk unggulan yang dikenal oleh masyarakat di seluruh Indonesia dan mampu bersaing dengan produk lain. Produk tersebut diharapkan memperoleh pasar atau konsumen potensial yang pada akhirnya dapat meningkatkan market share dari produk kerajinan kain perca ini.

\section{Metode}

\subsection{Analisis permasalahan mitra}

Analisis permasalahan mitra dilakukan melalui survey lapangan, wawancara dan diskusi. Permasalahan utama adalah pemasaran yang sangat terbatas, tidak adanya metode/cara mempromosikan produk.

\subsection{Solusi yang ditawarkan}

Solusi yang ditawarkan berdasarkan analisis situasi meliputi permasalahan, potensi yang ada dan peluangpeluang yang dapat dikembangkan.Adapun langkahlangkahnya adalah sebagi berikut. Pelatihan/Penyuluhan di bidang pemasaran yaitu:

(1) Pengemasan Produk Keset dengan memberi identitas dan logo

(2) Pelatihan Penggunaan Website untuk Pemasaran Online secara mandiri tidak bergantung pada tengkulak.

(3) Mengembangkan strategi pemasaran menggunakan media sosial

\section{(4) Memberikan promosi diskon}

\section{Hasil dan Analisa}

Untuk mencapai tujuan program IbM ini, maka dilakukan serangkaian kegiatan yaitu (1) perancangan strategi pemasaran dan (2) pelatihan penggunaan media online untuk pemasaran. Strategi pemasaran produk keset yang diterapkan pada mitra adalah:

\section{- Strategi produk}

Untuk mempertahankan dan meningkatkan omzet penjualan keset ke konsumen perlu dilakukan usaha penyempurnaan dan perubahan produk yang dihasilkan melalui kreasi dan inovasi ke arah yang lebih baik, sehingga dapat memberikan daya guna dan daya pemuas serta daya tarik yang lebih besar terhadap konsumen. Selain itu jumlah putaran jahitan yang diterapkan pada setiap model setiap keset perlu dijaga konsistensinya agar standar kualitas tetap terjamin.

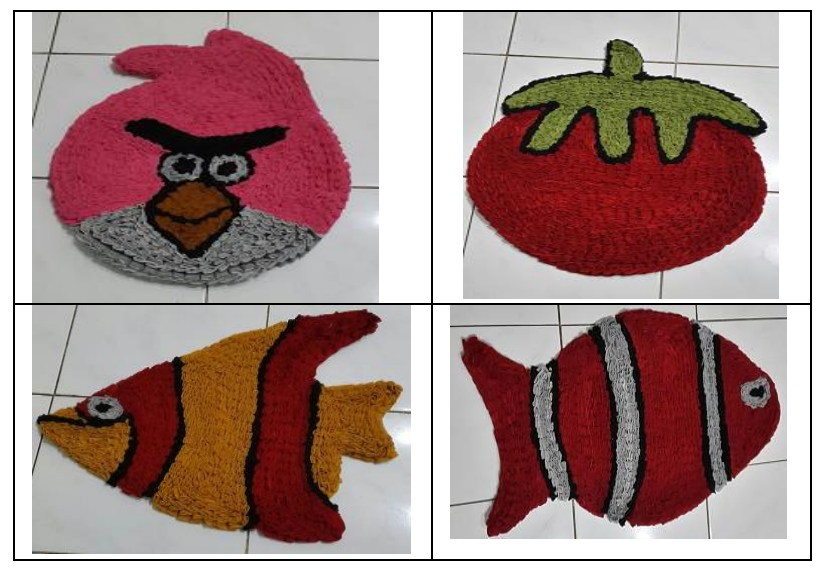

Gambar 1. Produk keset karakter dari kain perca

\section{- Strategi Harga}

Harga merupakan petunjuk tentang nilai suatu produk. Harga sebuah produk juga merupakan faktor kunci dalam pengambilan keputusan untuk membeli. Secara langsung harga sebuah produk akan menentukan nilai penjualan dan keuntungan. Untuk menetapan harga jual produk perlu dipertimbangkan biaya bahan baku, biaya produksi, dan biaya pemasaran dan jika sudah ada pengemasan maka inipun turut berkontribusi. Selain itu juga dipertimbangkan harga jual dari pesaing, agar keset hasil produksi dari mitra mampu bersaing dengan produsen keset lainnya. Memberikan potongan harga untuk konsumen pada pembelian yang banyak serta pada eventevent tertentu juga dapat menjadi daya tarik tersendiri.

\section{- Strategi Promosi}

Promosi merupakan kegiatan untuk memberitahukan atau menawarkan produk kepada masyarakat dengan tujuan 
menarik konsumen. Beberapa cara yang akan diupayakan untuk strategi promosi produk keset dari mitra adalah:

a. MMT

Berisi tentang model keset yang diproduksi oleh mitra.

b. Internet/website dan media sosial

Media ini untuk mempromosikan produk kepada masyarakat luas, agar produknya lebih dikenal oleh konsumen tanpa datang langsung ke lokasi produsen/outlet. Web yang telah dirancang adalah www.kesetantika.com. Foto-foto produk diperlukan untuk ditampilkan pada website. Informasi detail atau spesifikasi mengenai produk harus dicantumkan seperti berat rata-rata produk, jenis bahan, ukuran dan warna.

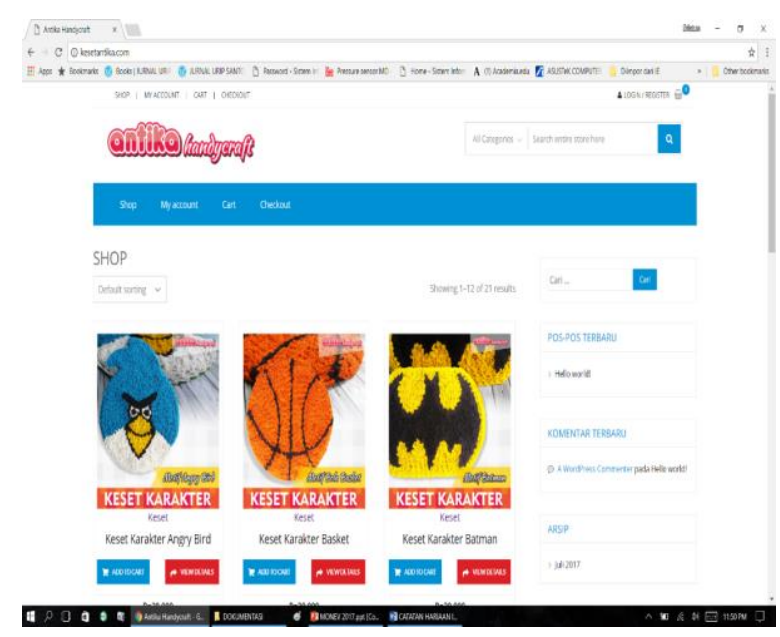

\section{Gambar 2. Tampilan website mitra}

c. Bisnis Online melalui tokopedia atau lainnya

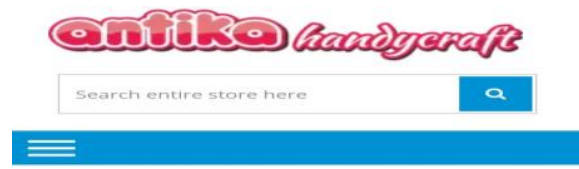

SHOP

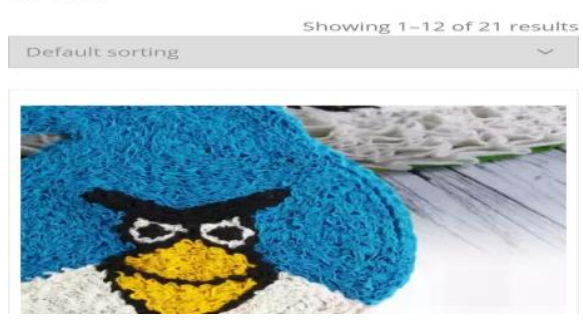

Gambar 3. Tampilan toko online mitra pada tokopedia

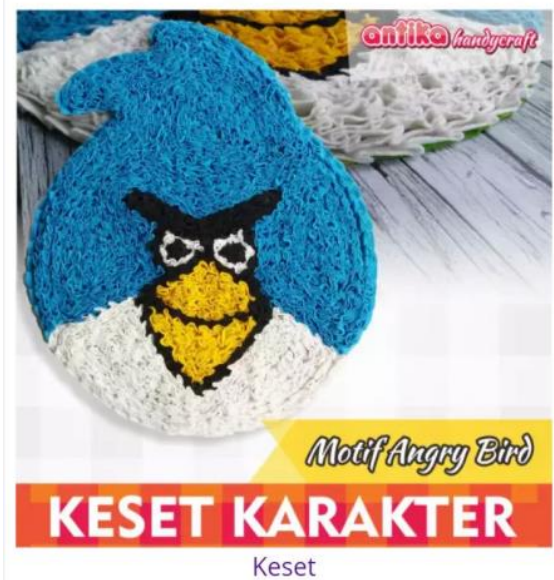

Keset Karakter Angry Bird

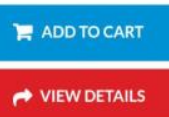

Rp30.000

\section{Gambar 3. Lanjutan}

Pelatihan pemasaran dengan media online

Pelatihan pemasaran yang diberikan kepada mitra meliputi penggunaan internet dan toko online. Memberikan pemahaman tentang bisnis atau transaksi yang dilakukan secara online dengan menggunakan internet sebagai media dan alat memasarkan produk atau jasa. Keuntungan yang diperoleh jika pemasaran dilaksanakan dengan cara online atau berbasis cloud marketplace adalah:

- Tidak membutuhkan modal yang besar (Media Sosial, Marketplace)

- Akses mudah dengan pelayanan penuh pada pelanggan. (Transaksi dilayani 24 Jam)

- Biaya operasional rendah (tanpa kantor dan pegawai)

- Kemudahan dalam proses pembayaran.

- Kreatifitas dalam promosi dan pengembangan produk lebih terbuka.

Pada pelatihan ini juga diberikan cara-cara melihat dan menambahkan produk pada website, membuat toko online. 


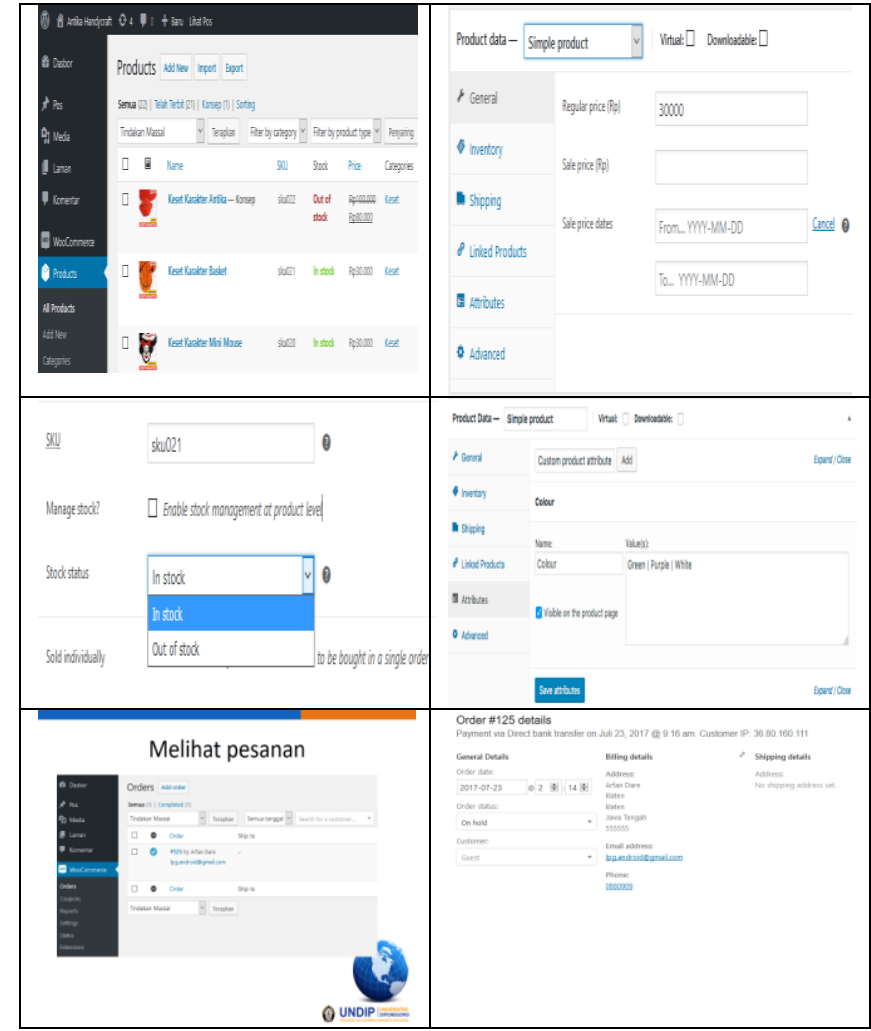

Gambar 4. Langkah-langkah untuk memasukkan produk dan melihat pesanan pada website

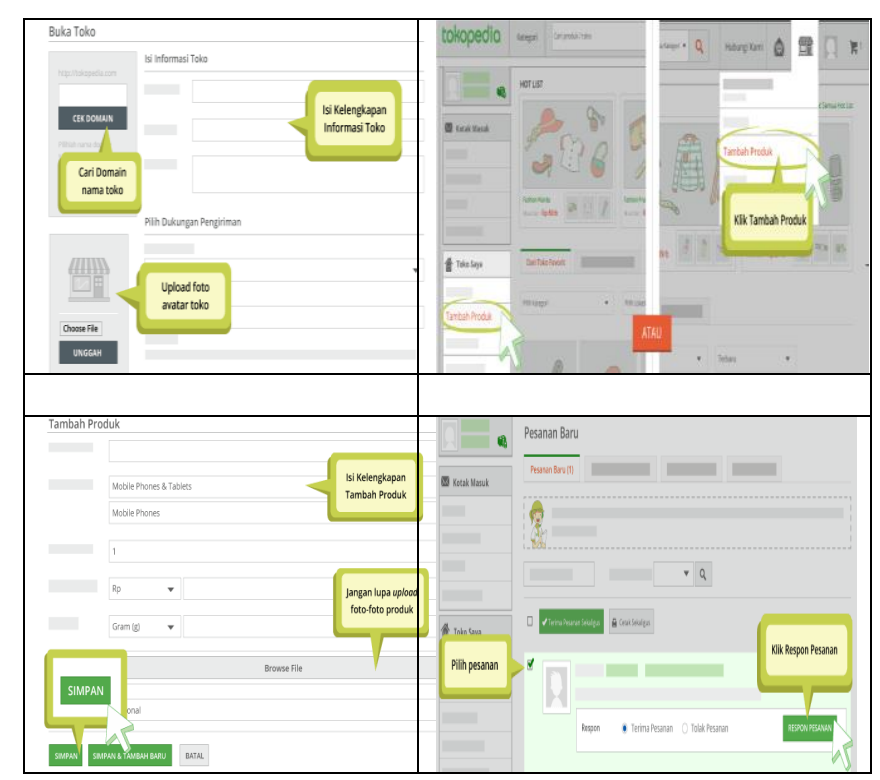

Gambar 5. Langkah-langkah membuka toko online pada tokopedia

\section{Kesimpulan}

Pemasaran produk kerajinan keset dari kain perca dapat ditingkatkan dengan memanfaatkan teknologi internet. Dengan teknologi ini tidak terhalangi oleh waktu dan tempat bagi pengrajin untuk menampilkan produknya. Kemudahan produk dilihat oleh berbagai kalangan dan asal konsumen mampu meningkatkan pemasaran sehingga omzet penjualanpun bertambah.

\section{Referensi}

[1]. O. K. Azer Bestavros, "Toward an Open Cloud Marketplace The Challenges of Public Clouds," IEEE Internet Comput., vol. 18, no. 1, pp. 72-77, 2014.

[2]. P. M. Mell and T. Grance, "The NIST definition of cloud computing," 2011 